\title{
A Simple Multi-Criteria Selection Model to Set Boundary Sample for Auto Parts
}

\author{
U. Kachawong and J. Pichitlamken
}

\begin{abstract}
When faced with several alternatives, decision making is not simple. At an automobile manufacturer, the review boundary sample activity for reducing cost and maintaining the best quality for customers is complex; it requires criteria-based judgments, e.g., defect ratio, claimed history of customers' parts, and customer complaint history data. We propose a decision support system for this multiple criteria selection problem by applying the Analytic Hierarchy Process (AHP) technique. Quality control engineers were surveyed to determine weights for criteria. With this system, the automobile manufacturer can use collected data to select alternatives. Even an inexperienced engineer can objectively identify the best selection.
\end{abstract}

Index Terms - Analytic Hierarchy Process (AHP), Boundary Sample, Multiple-Criteria Decision Making, Supplier Selection.

\section{INTRODUCTION}

Because an automobile manufacturer needs to maintain a goal of "Customers Come First," it must ensure that its suppliers provide products with the highest quality. However, the auto maker does not have explicit knowledge of suppliers' capability; some of them cannot control the quality of parts or defect outflow to the auto maker. They sometimes choose to scrap and repair parts in order to deliver them in conditions acceptable to the auto maker; this scrapping results in higher costs to suppliers themselves, even though the parts may not be unacceptably defective.

Boundary Sample is defined as the defective limit of a vehicle's parts specified by the auto maker to ensure that suppliers make proper judgments on the quality of their parts, when screening parts are consigned to the auto maker. However, the boundary samples are not set for every part. Three conditions for setting the boundary sample are (1) when suppliers have been unable to control their production process; (2) when a defective part is identified and declared as clearly not meeting the standard, and (3) when the parts are in areas visible to customers.

In light of customer satisfaction, the auto maker always sets stricter boundary samples than required. There are three main standards for quality control: The Complete Vehicle Inspection Standard (CVIS) is used to control vehicle quality at the auto maker, by reference to the Japanese fitting standards; the Shipping Quality Audit (SQA) controls vehicle quality, by reference to customer satisfaction. Generally, the CVIS exercises stricter control than the SQA. Finally, the Approval Inspection Standard (ATIS) specifies parts quality for suppliers, by reference to engineering drawings. If a part is shown in the CVIS or on a drawing, the auto maker would not set a boundary sample; else, the company would set boundary samples based on a stricter SQA, to ensure the quality for customers.

Suppliers negotiate with the auto maker of defects of parts and price. The Quality Control (QC) department needs to make judgments on whether to accept or reject these proposals (the process called boundary sample review) by considering multiple criteria, e.g., defect ratio, benefit-cost analysis, supplier's history, extent of defects, and acceptable defects based on the SQA. Generally, QC engineers approve suppliers' proposals regarding the extent of defects by referring to the SQA; however, few engineers have sufficient understandings to judge the acceptable extent of defects in the SQA.

As a result, a decision support system (DSS) is needed to enable correct judgment in minimum time and with limited skill and experience. Ideally, judgments should be objective and take into account several selections or alternatives to provide the best selection. Suppliers' data and the SQA's constraints are integrated into this system through the Analytic Hierarchy Process (AHP) framework. We have implemented our software prototype in Microsoft Excel because of its user friendliness and widespread presence. This DSS is ideal for efficient judgment of boundary samples by engineers with limited skills or experience.

\section{LITERATURE SURVEY}

Dickson [1] studies the vendor selection decisions. He identifies at least 50 distinct meaningful factors in vendor selection (i.e., characteristics of vendor performance) from the purchasing literature. Dickson summarizes the importance of these criteria for vendor selection.

Ragsdale [2] and Bhutta and Huq [3] suggest AHP as a structured approach for determining the scores and weights for the multi-criteria scoring model, which is a simple procedure for scoring (or rating) each alternative in a decision making process. First, the decision maker specifies weights, $w_{i}$ that indicate the relative importance of each criterion. These weights must sum to 1 . The score for alternative $j$ on criterion $i$ is denoted by $S_{i j}$. For each alternative $j$, we compute its weighted score as $\sum w_{i} S_{i j}$. Then, the alternative with the largest score is selected.

Sometimes, a decision maker finds it difficult to subjectively determine the criterion scores and weights needed in the multi-criteria scoring model, especially when subjective and/or intuitive considerations have to be incorporated. AHP standardizes criterion weights and scores so that they can be compared and used for making decisions. Narasimhan [4] applies AHP to the supplier selection activity because it offers a methodology to rank alternative courses of 
action based on the decision maker's judgments concerning the importance of the criteria, and the extent to which they are met by each alternative.

In Lee, Ha, and Kim [5], the supplier selection and management system (SSMS) relies on the AHP model to calculate the weights of both tangible and intangible criteria for supplier selection and to rank the suppliers' performance. The weights of these criteria are applied to select the key factors for reinforcing the quality of each part.

\section{SURVEY RESULTS}

To determine the AHP weights, $w_{i}$, we use three sets of questionnaire surveys: the criteria ranking (Section IIIA), extent of defects (Section IIIB), and other criteria (Section IIIC). Section IIID describes the AHP scoring for criterion weights for pair-wise comparisons.

\section{A. The Criteria Ranking}

The five quality criteria considered are the extent of defect, defect ratio, benefits, claimed history data and customer complaint history data. The extent of defect questionnaire is designed to find acceptable extents smaller than the standard of SQA. We find that the extent of defect criteria is difficult to establish because it requires respondents' experience. The questionnaires for other quality criteria include acceptable defect ratios, sufficient benefits, the acceptable number of customer complaint cases, and the acceptable number of claimed part cases when we accept the extent of defect presented by suppliers. Because the extent of defect criterion requires judgments from work experience, we assign weights relative to job positions (the more senior the positions, the higher the weights), e.g., 1 for engineers, 1.5 for chief engineers, and 2 for positions higher than assistant managers.

\section{B. Design of Extent-of-Defect Questionnaire}

Initially, we designed the extent-of-defect questionnaire for one part at a time, but we found it impractical for respondents to answer every question from suppliers' proposal. The questionnaire was then redesigned and distributed to eighteen qualified engineers in the QC Department for setting the grade of suppliers who present the extent of defect for establishing boundary samples. Usually, AHP scales are from 1 to 9, but we deem it too fine; thus we use only the grades of A, B, C, D, and E to represent surely accept (to consider the proposal for a boundary sample review), accept, may accept, need supports from leaders and not accept (i.e., refuse to consider the proposal) opinions, respectively. The questionnaire asks only for the minimum and maximum extent of defect (surely accept and not accept grades); the remaining grades are interpolated from the minimum to maximum values.

Both types of questionnaires have 44 questions with 6 multiple choices. For each part item, the surely accept questionnaire asks "What is the worst extent of defect that you find acceptable?" and the not accept questionnaire asks "What is the beginning extent of defect that you find not acceptable?"

Questions are classified by the zones of defect (e.g., Zone $A$ is area which can be seen while sitting on the front seat) and the type of auto parts (e.g., interior and exterior, or paint), following the SQA. Each choice is assigned according to the extent of defect in the SQA. For example, if the SQA specifies that the scratch mark of Item 1 in Zone A should be no more than $5 \mathrm{~mm}$. in diameter, then the choices for the surely accept questionnaires are set as a) 0.1-1.0, b) 1.1-2.0, c) 2.1-3.0, d) 3.1-4.0, e) 4.1-5.0 and f) Unacceptable, whereas the choices for the not accept questionnaire are similarly set as above, but the last choice is "More than the standard." The complete questionnaires can be found in [6].

The empirical results of minimum and maximum extent of defect questionnaire are shown in Fig. 1 and 2. The horizontal axis is the item number, and the vertical axis is the fraction of respondents selecting each choice (shown in different colors). The results from the surely accept survey show that most respondents do not accept any defects although some engineers did provide meaningful upper bounds. The not accept results in Fig. 2 are more informative in that it provides the lower bound of defect size, beyond which parts are certainly rejected. We see that maximum extent of defect depends on the zone and part types; some zones and part types are more critical and visible that small extent of defect is required.

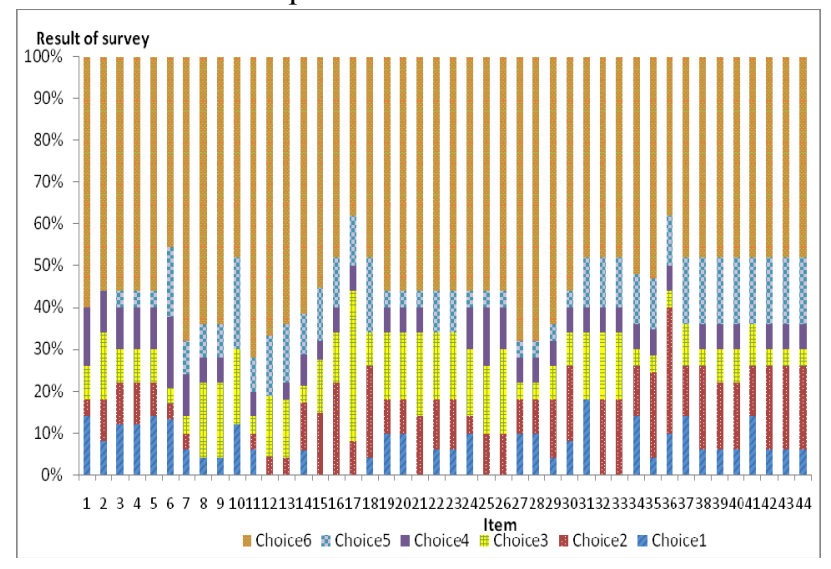

Fig. 1.The survey results in surely accept questionnaire (minimum extent of defect).

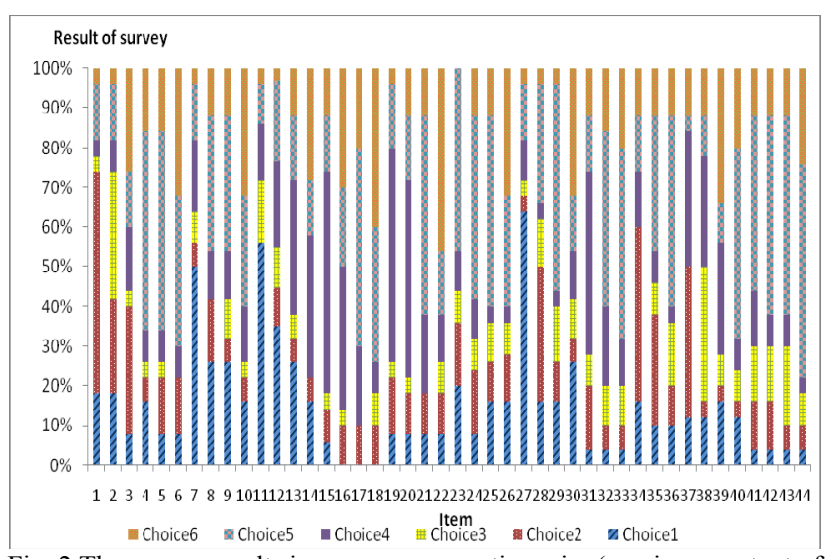

Fig. 2.The survey results in not accept questionnaire (maximum extent of defect).

\section{The Other-Criteria Questionnaire Design}

The rest of the questionnaires are on benefits, defect ratio, claimed history, and customer complaint history. Twenty-eight QC engineers are asked about their preferences on the supplier's proposals on the scales of A to E, similar to the extent-of-defect questionnaire. Grade A (surely accept) is 
assigned when respondents can accept a proposal for a boundary sample review by themselves; Grade B (accept) is when respondents can decide after requesting one more piece of information (e.g., process capability ratio, $C_{p}$ ); Grade $\mathrm{C}$ (may accept) is when respondents can make a decision after getting more than one piece of information; Grade D (need support from leaders) is when respondents need support from leaders; and Grade E (not accept) is when respondents can reject a proposal by themselves. For example, on Grade A of the cost benefit criteria, respondents are asked "What fraction of cost reduction that you are willing to immediately accept the proposal for boundary sample review?" and to choose one out of nine choices.

TABLE 1. THE RESULT OF SURVEYS ON THE BENEFIT CRITER
\begin{tabular}{|c|c|c|}
\hline Grade & Benefits (\%) & $\begin{array}{r}\text { Fraction of } \\
\text { respondents }\end{array}$ \\
\hline A & $80 \%$ and up & $71 \%$ \\
\hline B & $51 \%-60 \%$ & $46 \%$ \\
\hline C & $41 \%-50 \%$ & $39 \%$ \\
\hline D & $21 \%-30 \%$ & $46 \%$ \\
\hline E & $0 \%-10 \%$ & $71 \%$ \\
\hline
\end{tabular}

TABLE 2. THE RESUlt OF SURVEYS ON THE DEFECT RATIO CRITERION

\begin{tabular}{|c|c|c|}
\hline Grade & Defect Ratio & $\begin{array}{c}\text { Fraction of } \\
\text { respondents }\end{array}$ \\
\hline A & $80 \%$ and up & $64 \%$ \\
\hline B & $31 \%-40 \%$ & $46 \%$ \\
\hline C & $21 \%-30 \%$ & $46 \%$ \\
\hline D & $11 \%-20 \%$ & $54 \%$ \\
\hline E & $0 \%-10 \%$ & $89 \%$ \\
\hline
\end{tabular}

TABLE 3. The Results of CuSTOMER COMPLAint CASES In 8 MONTHS

\begin{tabular}{|c|c|c|}
\hline Grade & $\begin{array}{c}\text { \# of customer } \\
\text { complaint cases }\end{array}$ & $\begin{array}{c}\text { Fraction of } \\
\text { respondents }\end{array}$ \\
\hline A & 0 & $82 \%$ \\
\hline B & 1 & $54 \%$ \\
\hline C & $2-3$ & $64 \%$ \\
\hline D & $4-5$ & $36 \%$ \\
\hline E & More than 7 cases & $68 \%$ \\
\hline
\end{tabular}

TABLE 4. THE RESULT OF SURVEY OF PART CLAIMED CASES IN 8 MONTHS

\begin{tabular}{|c|c|c|}
\hline Grade & $\begin{array}{c}\text { \# of part } \\
\text { claimed cases }\end{array}$ & $\begin{array}{c}\text { Fraction of } \\
\text { respondents }\end{array}$ \\
\hline A & $1-10$ & $54 \%$ \\
\hline B & $11-20$ & $57 \%$ \\
\hline C & $21-30$ & $39 \%$ \\
\hline D & $31-40$ & $43 \%$ \\
\hline E & More than 80 & $61 \%$ \\
\hline
\end{tabular}

The survey results are shown in Tables 1-4. The selected choices are ones which win the majority votes. Benefits are in terms of fraction of yearly target of cost reduction. Grade
A of benefits criteria should reduce cost by more than $80 \%$ of the yearly target, i.e., if supplier presents cost reduction of more than $80 \%$, almost all engineers will accept this proposal by themselves. The survey results of defect ratio (Table 2) indicate that the QC engineers want to do a boundary sample review if the supplier's defects are high; on the other hand, when the defect ratio is low, suppliers are left to solve their problem by themselves. Grade $\mathrm{C}$ of customer complaint criteria is 2 to 3 cases (Table 3 ); if customer complaint history of this supplier is 2 to 3 cases in 8 months, almost all of engineers will accept the supplier's proposal after requesting more than one item of information. Grade E on part claimed criteria are 80 cases and higher; if part claimed history of the suppliers is more than 80 cases in 8 months, almost all engineers will not accept the supplier's proposal with support from leaders.

\section{The Criterion Weights for AHP scoring}

The pair-wise criterion weight is designed to find weight scores on each criterion by using the AHP framework. The questionnaire consists of twenty questions, which are answered by twenty-eight QC engineers. The pair-wise comparison questions are of the following nature: "How much do you prefer criteria 1 over criteria 2 for approval of boundary samples?" The preference scales are from 1 to 9 , ranging from "Equally Preferred" (1) to "Extremely Preferred" (9). Let the preference of criterion $i$ over criterion $j$ be $P_{i j}$; then the preference of $j$ over $i$ is simply $P_{j i}=1 / P_{i j}$. To compute the criterion weights, we first calculate the column sums, $S_{j}, j=1,2, \ldots, 5$, then the normalized preference of criterion $i$ over criterion $j$ is $P_{i j} / S_{j}$. The weight of criterion $i$ is simply

$$
w_{i}=\frac{1}{5} \sum_{i=1}^{5} \frac{P_{i j}}{S_{j}} .
$$

See [2] for more details. The empirical result and the criterion weights for pair-wise comparisons are shown in Table 5. As expected, the quality-related criteria receive most of the weights; i.e., the extent-of-defect weight is $48.8 \%$ whereas the defect-ratio weight is $24.9 \%$.

\section{AHP SCORING PROCESS}

The grades of alternatives are determined by pair-wise comparison scales (Table 6) together with differences of alternatives' grade (Table 7). The AHP pair-wise comparison uses scales of 1, 3, 5, 7 and 9, representing "equally preferred" when two proposals are given the same grade; "moderately preferred" represents the difference of 1 grade, "strongly preferred" 2 grades, "very strongly preferred" 3 grades and "extremely preferred" 4 grades (Table 7). For example, the supplier $\mathrm{S}_{1}$ presents the extent of defects and results in grade $A$, whereas the supplier $S_{2}$ presents his and receives grade E. Therefore, the AHP score is "9" because they differ by 4 grades.

When a supplier submits his proposal, the part item is identified by the zone of defect and part types, and the proposal's grade is determined by using pair-wise comparison scales (Table 6) together with difference of alternatives' grade (Table 7). Once the criterion scores are determined, they are multiplied by the weights shown in 
Table 5. The proposal with the largest total score is selected.

TABLE 5. THE SURVEY RESULTS ON THE CRITERION PREFERENCES
\begin{tabular}{|c|c|c|c|c|c|}
\hline & $\begin{array}{c}\text { Extent } \\
\text { of } \\
\text { defects }\end{array}$ & Benefits & $\begin{array}{c}\text { Defect } \\
\text { Ratio }\end{array}$ & $\begin{array}{c}\text { \# of } \\
\text { customer } \\
\text { complaints }\end{array}$ & $\begin{array}{c}\text { \# of } \\
\text { claimed } \\
\text { parts }\end{array}$ \\
\hline $\begin{array}{c}\text { Extent of } \\
\text { defects }\end{array}$ & 1 & 5 & 5 & 5 & 5 \\
\hline Benefits & 0.2 & 1 & 0.17 & 0.25 & 0.25 \\
\hline $\begin{array}{c}\text { Defect } \\
\text { Ratio }\end{array}$ & 0.2 & 6 & 1 & 3 & 5 \\
\hline $\begin{array}{c}\text { \# of } \\
\text { customer } \\
\text { complaints }\end{array}$ & 0.2 & 4 & 0.33 & 1 & 2 \\
\hline $\begin{array}{c}\text { \# of } \\
\text { claimed } \\
\text { parts }\end{array}$ & 0.2 & 4 & 0.2 & 0.5 & 1 \\
\hline $\begin{array}{c}\text { Criterion } \\
\text { Weight }\end{array}$ & $\mathbf{0 . 4 8 8}$ & $\mathbf{0 . 0 4 6}$ & $\mathbf{0 . 2 4 9}$ & $\mathbf{0 . 1 2 3}$ & $\mathbf{0 . 0 9 4}$ \\
\hline
\end{tabular}

\begin{tabular}{|c|c|}
\hline \multicolumn{2}{|c}{ TABLE 6. PREFERENCE SCORES. } \\
\hline Value & Preference \\
\hline 1 & Equally Preferred \\
\hline 3 & Moderately Preferred \\
\hline 5 & Strongly Preferred \\
\hline 7 & Very Strongly Preferred \\
\hline 9 & Extremely Preferred \\
\hline
\end{tabular}

TABLE 7. GRADE DIFFERENCES AND PREFERENCE SCORES.

\begin{tabular}{|c|c|c|c|c|c|}
\hline & A & B & C & D & E \\
\hline A & 1 & 3 & 5 & 7 & 9 \\
\hline B & - & 1 & 3 & 5 & 7 \\
\hline C & - & - & 1 & 3 & 5 \\
\hline D & - & - & - & 1 & 3 \\
\hline E & - & - & - & - & 1 \\
\hline
\end{tabular}

\section{ExCEL-BASEd Prototype Software}

We implement our AHP framework on Excel because it is convenient to collect, manipulate, and display data. Users specify supplier' name, the values for extent of defect, benefits, and defect ratio in the Excel template. The steps in using our software are described as follows:

\section{A. Input the extent of defect}

A user specifies the extent of defect on a blank form that corresponds to the item's zone of defect and type of part. The input value is checked with the maximum thresholds that are already stored in the Excel worksheet. If the proposed extent of defect is less than the acceptable value, the software will continue to set a grade based on the extent of defects and to determine AHP scores by pair-wise comparisons. On the other hand, if the extent of defect is larger than the allowable limits, the proposal will not be approved, and the reviewing process is stopped.

\section{B. Input a supplier's name}

A user provides a supplier's name to check its record: the customer complained record and the claimed record which are already stored in the Excel program. It generates a grade of an alternative for these criteria. Then a pair-wise comparison is done to translate a grade of an alternative to an AHP scores.

\section{Input a defect ratio}

A user inputs the defect ratio that a supplier presents for the approval of a boundary sample. The software generates a grade of alternative and an AHP score.

\section{Input benefits}

The suppliers always present benefits in term of cost reduction per year, and our Excel template translates it to a fraction of target of cost reduction per year (250,000 Baht) and generates a grade of an alternative in benefits criteria and an AHP score.

\section{E. The decision-making process}

We select the proposal with the largest AHP scores.

\section{CONCLUSION AND FUTURE WORK}

We have developed an Excel-based template for users to select the best proposal based on the AHP framework. Initial satisfaction surveys reveal that our software can reduce time and produce objective selections; even a new or an inexperienced engineer can use our system to identify the best selection. We plan to make it more user-friendly and cover other auto parts.

\section{ACKNOWLEDGEMENT}

Kochavong thanks the International Graduate Program in Industrial Engineering at Kasetsart University for the financial support.

\section{REFERENCES}

[1] Dickson, G. W. "An analysis of vendor selection systems and decisions," in Journal of Purchasing vol 2, 1966, pp. 5-17.

[2] Ragdale, C. T. Spreedsheet Modeling \& Decision Analysis: A Practical Introduction to Management Science. South-Western College Publication, 2007.

[3] Bhutta, K. S. and F. Huq. "Supplier selection problem: A comparison of the total cost of ownership and analytic hierarchy process approaches," in Supply Chain Management vol 7, 2002, pp. 126-135.

[4] Narasimhan, R. "An analytical approach to supplier selection," in Journal of Purchasing and Materials Management, vol 19, 1983, pp. 27-32.

[5] Lee, E.-K., S. Ha, and S.-K. Kim. "Supplier Selection and Management System Considering Reletionships in Supply Chain Management," in Transactions on Engineering Management, vol 48, 2001, pp. 307-318.

[6] U. Kachawong A Simple Efficient Selection Model to Set Boundary Sample for Multiple Criteria Alternatives, Master Thesis, Kasetsart University. 2011r

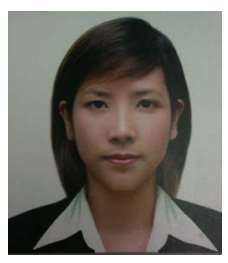

Unchita Kochawong received her B.Eng. in Industrial Engineering from King Mongkut's Institute of Technology at Ladkrabang (KMITL) and her M.Eng. in Engineering Management from International Graduate Program in Industrial Engineering, Department of Industrial Engineering, Faculty of Engineering, Kasertsart University. She can be reached at unchitha_bee@hotmail.com.

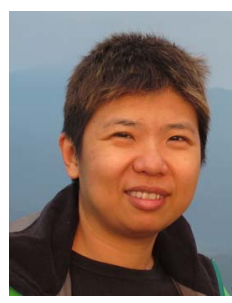

Juta Pichitlamken received her Ph.D. from Industrial Engineering and Management Science Department, Northwestern University, USA. She currently teaches at the Department of Industrial Engineering, Kasetsart University, Bangkaen Campus. Her interests include discrete-event stochastic simulation, operations research, and stochastic processes. Her webpage is $\mathrm{http}: / /$ pirun.ku.ac.th/ fengjtp/ and email is juta.p@ku.ac.th 